\title{
Research
}

\section{Sensitivity of chest X-ray for detecting lung cancer in people presenting with symptoms:}

\author{
a systematic review
}

\begin{abstract}
\section{Background}

Despite increasing use of computed tomography (CT), chest $X$-ray remains the first-line investigation for suspected lung cancer in primary care in the UK. No systematic review evidence exists as to the sensitivity of chest $X$-ray for detecting lung cancer in people presenting with symptoms.
\end{abstract}

\section{Aim}

To estimate the sensitivity of chest X-ray for detecting lung cancer in symptomatic people.

\section{Design and setting}

A systematic review was conducted to determine the sensitivity of chest $\mathrm{X}$-ray for the detection of lung cancer

\section{Method}

Databases including MEDLINE, EMBASE, and the Cochrane Library were searched; a grey literature search was also performed.

\section{Results}

A total of 21 studies met the eligibility criteria. Almost all were of poor quality. Only one study had the diagnostic accuracy of chest X-ray as its primary objective. Most articles were case studies with a high risk of bias. Several were drawn from non-representative groups, for example, specific presentations, histological subtypes, or comorbidities. Only three studies had a low risk of bias. Two primary care studies reported sensitivities of $76.8 \%$ (95\% confidence interval $[\mathrm{Cl}]=64.5$ to $84.2 \%$ ) and $79.3 \%$ $95 \% \mathrm{Cl}=67.6$ to $91.0 \%$ ). One secondary care study reported a sensitivity of $79.7 \%$ (95\% $\mathrm{Cl}=72.7$ to $86.8 \%$ ).

\section{Conclusion}

Though there is a paucity of evidence, the highest-quality studies suggest that the sensitivity of chest X-ray for symptomatic lung cancer is only $77 \%$ to $80 \%$. GPs should conside if further investigation is necessary in high-risk patients who have had a negative chest $\mathrm{X}$-ray.

\section{Keywords}

diagnostic imaging; early diagnosis; lung cancer; primary care; $\mathbf{X}$-rays

\section{INTRODUCTION}

Lung cancer is the single largest cause of cancer mortality both worldwide ${ }^{1}$ and in the UK. ${ }^{2}$ Compared with many other cancers, improvements in lung cancer survival over recent decades have been modest. The agestandardised 5-year survival rate has only increased from approximately 5\% to 10\% since $1971,{ }^{2}$ compared with improvements from $53 \%$ to $87 \%$ in the 5 -year survival rate for breast cancer in the same period. ${ }^{3}$

Diagnosis of lung cancer at earlier stages of disease is associated with improved survival. Optimising early detection is therefore considered an important strategy in improving outcomes. ${ }^{4}$ Chest X-ray is comparatively cheap, accessible, ${ }^{5}$ and has a low radiation dose. ${ }^{6}$ It remains the firstline investigation for lung cancer in primary care and the most common radiological route to diagnosis.? This is reflected in current National Institute for Health and Care Excellence lung cancer guidelines, which recommend chest X-ray for initial evaluation in all patients, aside from those aged $>40$ years who have unexplained haemoptysis. ${ }^{8}$ Outcomes for lung cancer in the UK remain poor compared to other advanced economies, ${ }^{9}$ where modalities such as computed tomography (CT) are used more extensively. ${ }^{10}$

Despite its predominance in guidelines and clinical practice, no systematic review

SH Bradley, MRCP, clinical research fellow; A Grice, MRCGP, GP academic fellow; RD Neal, PhD, FRCGP, professor of primary care oncology, Academic Unit of Primary Care, University of

Leeds, Leeds. S Abraham, MSc, health economist, Test Evaluation Group; R Rodriguez Lopez, MSc, information specialist; B Shinkins, DPhil, associate professor, Test Evaluation Group, Academic Unit of Health Economics, University of Leeds, Leeds. MEJ Callister, FRCP, consultant respiratory physician, Leeds Teaching Hospitals NHS Trust, Leeds. WT Hamilton, FRCP. FRCGP professor of primary care diagnostics, University of Exeter, Exeter. has determined the sensitivity of chest X-ray alone for lung cancer in patients presenting with symptoms, which is the aim of the present study.

\section{METHOD}

A systematic review was conducted in June 2017 and updated in December 2018.

The sensitivity of chest X-ray for lung cancer was estimated by identifying studies that:

- reported the number of patients who were investigated with chest X-ray owing to symptoms in the year before their diagnosis of lung cancer; and

- reported the contemporaneous results of the chest $\mathrm{X}$-rays.

Screening studies were not included. The authors registered the study protocol with PROSPERO. ${ }^{11}$ An amendment to the protocol was subsequently made to correct an error. In addition, articles were screened based on their title and abstract, rather than on the basis of title only, as reported in the protocol.

\section{Search strategy}

In July 2017 the authors searched CINAHL, Cochrane Database of Systematic Reviews (CDSR), Cochrane Controlled Register of Trials (CENTRAL), Database of Abstracts

\section{Address for correspondence}

Stephen Bradley, Academic Unit of Primary Care Leeds Institute of Health Sciences, Room 10.39, Worsley Building, University of Leeds, Leeds LS2 9JT, UK.

Email: medsbradaleeds.ac.uk

Submitted: 7 February 2019: Editor's response: 17 March 2019; final acceptance: 2 May 2019. (c)British Journal of General Practice This is the full-length article (published online 22 Oct 2019) of an abridged version published in print. Cite this version as: Br J Gen Pract 2019; DOI: https://doi.org/10.3399/bjgp19X706853 


\section{How this fits in}

Chest $\mathrm{X}$-ray remains the first-line investigation for suspected lung cancer in the UK. Outcomes for lung cancer are relatively poor compared with the healthcare systems of many other advanced economies, which make more extensive use of other imaging modalities such as computed tomography (CT). This systematic review found that there is limited high-quality evidence published on the diagnostic accuracy of chest $\mathrm{X}$-ray. The few high-quality studies identified suggest that chest $\mathrm{X}$-ray misses lat least initially) lung cancer in $>20 \%$ of people. As earlier diagnosis is closely associated with improved survival, it is therefore possible that the use of chest X-ray in UK practice may delay the diagnosis of lung cancer in some patients. These findings support calls to increase open-access CT for GPs, but, given resource restrictions and the potential to cause harm through overdiagnosis, further research is required to help identify which patients who have had a non-diagnostic chest X-ray should be referred for additional investigation.

of Reviews of Effects (DARE), Health Technology Assessment (HTA), NHS Economic Evaluation Database (NHS EED), EMBASE, MEDLINE, MEDLINE in process, MEDLINE Epub ahead of print, PubMed, and Science Citation Index (SCI). These resources were searched with no language restrictions from 1999 using a search strategy with subject headings and freetext words for the concepts 'chest X-ray' and 'lung cancer'. Only studies published after 1999 were included in order to ensure that evidence reflected contemporary radiological technology and practice. The searches were peer reviewed and updated in December 2018 in all the databases. The full search strategies are available from the authors on request. The reference lists of included articles were screened. The websites of several organisations ${ }^{12-26}$ were manually searched to identify any potentially eligible reports, guidelines, and audits (grey literature search).

\section{Inclusion and exclusion criteria}

The authors considered any study that reported the number of adult patients who had a chest X-ray following a symptomatic presentation to a clinician in the year before diagnosis with lung cancer. The period of 1 year was selected with reference to estimates of detectable pre-clinical phase of lung cancer (mean sojourn time), ${ }^{27}$ estimated to be between 5.5 months ${ }^{28}$ and 2.2 years. ${ }^{29}$ Studies where it was unclear if the duration between chest X-ray and diagnosis was $<1$ year were excluded. Studies based on screening populations were excluded. Studies of patients aged $<18$ years, other intrathoracic malignancies such as mesothelioma and lymphoma, metastatic lung disease from a non-lung cancer primary tumour, and imaging undertaken for staging or diagnostic surveillance for recurrent lung cancer were also excluded. In order to evaluate the diagnostic accuracy of chest X-ray in clinical practice, the authors excluded studies that examined the proportion of chest $X$-rays where lesions were 'missed' but identified in retrospect.

Chest X-rays were considered positive if any abnormality considered suspicious for lung cancer was noted at the time of reporting and were considered negative if no features suspicious of lung cancer were noted at the time of reporting. Where the findings of chest $X$-ray were not reported in a way that could be classified as positive or negative according to this definition, the authors reported the presence or absence of abnormalities on the chest $X$-rays.

The authors did not exclude any studies based on the reference standard used.

\section{Study selection}

Titles and abstracts of all studies were screened with reference to the inclusion and exclusion criteria. A random $20 \%$ of all titles and abstracts were independently screened by a second author. As it was anticipated that relevant data in some cases would have been reported incidentally, rather than as a primary finding of studies, the reviewers maintained a low threshold for selecting citations for full-text review. In the case of disagreements or uncertainty, a third reviewer was consulted. A full-text review of all selected texts was undertaken by the first author to determine final eligibility.

\section{Data extraction}

Data from included studies were extracted using a form including demographics and presenting symptoms of participants, sensitivity of chest $X$-ray, sample size, setting, for example, primary or secondary care, and the reference standard implemented to determine true disease status.

\section{Analysis}

The outcome was the sensitivity of chest $X$-ray for the detection of lung cancer. This was determined by evaluating the stated 


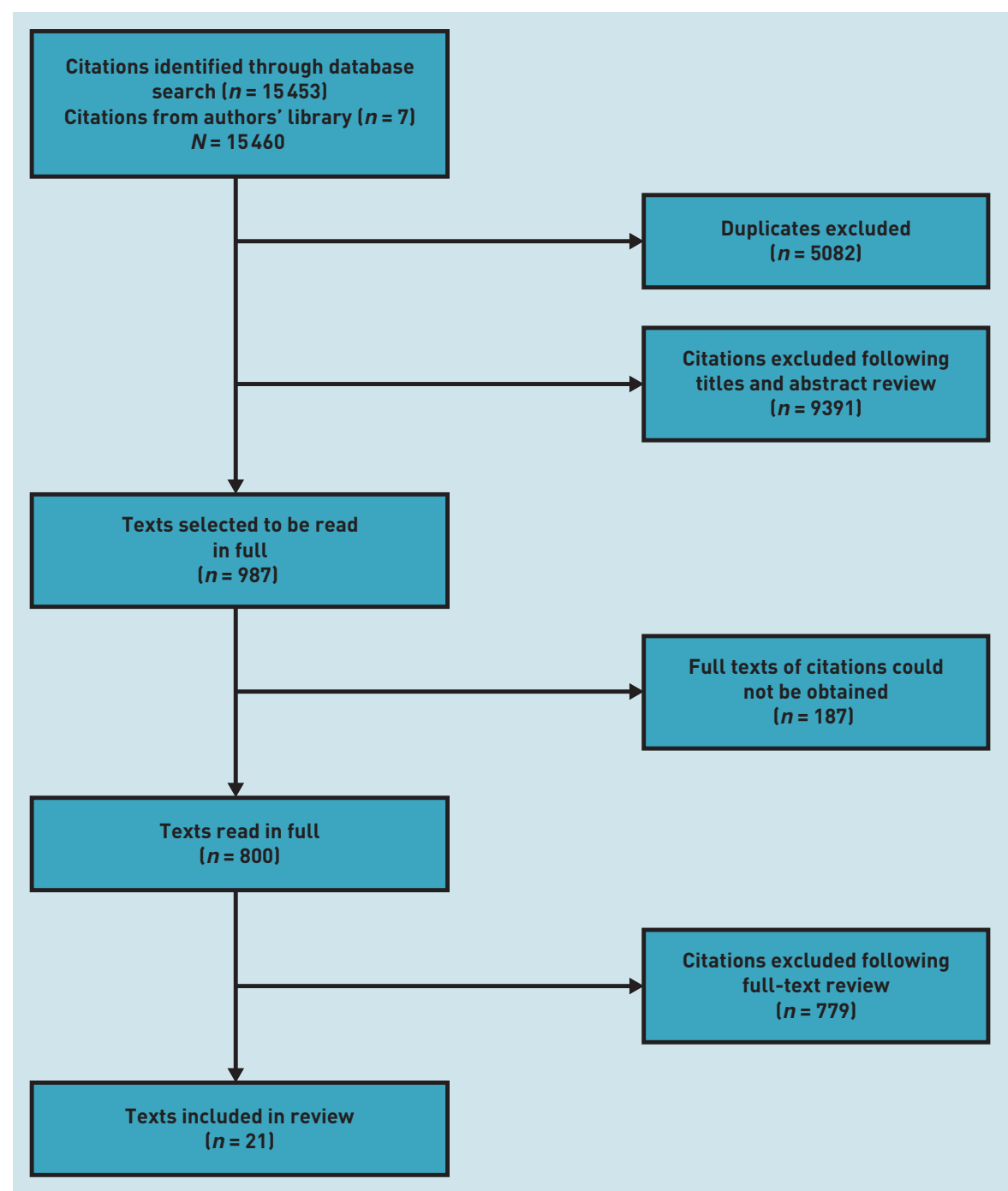

Figure 1. PRISMA diagram of study inclusion. numbers of patients in each study who presented with symptoms, those who had had chest $X$-ray in the year before diagnosis with lung cancer, and for those for whom the chest X-ray had yielded a positive result. Ninety-five per cent confidence intervals (CI) for each within-study sensitivity estimate were also calculated. Metaanalysis was planned to be undertaken if possible. In the event of high between-study heterogeneity or a low quality of eligible studies, the authors planned to proceed with a descriptive synthesis of the studies only. A modified version of the QUADAS-2 too ${ }^{30}$ for diagnostic accuracy studies was used for quality assessment.

\section{RESULTS}

The selection of the 21 studies $^{31-51}$ included in this review is presented in the PRISMA diagram in Figure 1. Though 987 citations were selected for full-text review, 187 citations could not be obtained despite attempts to contact authors by email. The majority of the citations that were not obtained were in non-English publications ( $n=119,63.6 \%)$, while a substantial proportion ( $n=90,48.1 \%$ ) of these citations reported no clinical data at all in their abstracts, but were selected for fulltext review owing to the comprehensive approach taken by the reviewers.

The most common reason for exclusion ( $n=739)$ was that the study did not contain research or data that were pertinent to the study question. This included a large number ( $n=117)$ of general texts, such as reviews, correspondence, and educational articles that did not address the study question.

Some citations ( $n=59)$ were excluded because the interpretation of the imaging was undertaken retrospectively, when the diagnosis of lung cancer was already known. Seventeen studies were not eligible because patients had been chosen for inclusion on the basis of a chest X-ray that was known to be positive or negative for lung cancer. Four studies were ineligible because they evaluated individual performance at interpreting chest $\mathrm{X}$-rays using films, where the presence or absence of lesions was already known to the study investigators. Other studies were excluded because: the cancers considered were not a primary lung cancer $(n=44)$, they were case reports of a single patient $(n=53)$, the duration between chest $X$-ray and diagnosis was $>1$ year or unclear $(n=28)$, they were drawn from screening data $(n=22)$, or patients were $<18$ years of age $(n=2)$.

Given the high heterogeneity between studies included and their low quality, meta-analysis was not appropriate.

\section{Summary of eligible studies}

A final total of 21 studies met the inclusion criteria (Table 1). The number of patients in each study varied notably (range $n=2$ to $n=208$ ). Study estimates of sensitivity ranged from $40 \%$ to $100 \%$. Most of the studies were case series. Only one study had the primary objective of estimating the diagnostic accuracy of chest X-ray for lung cancer. ${ }^{43}$

Many of the studies only included particular subgroups of the relevant patient population, such as atypical tumour histology, or specific comorbidities and symptom presentations. Only four studies ${ }^{41,43,44,50}$ were based on representative populations of patients with lung cancer, rather than particular subgroups.

A population-based observational case series identified all patients in the Danish 


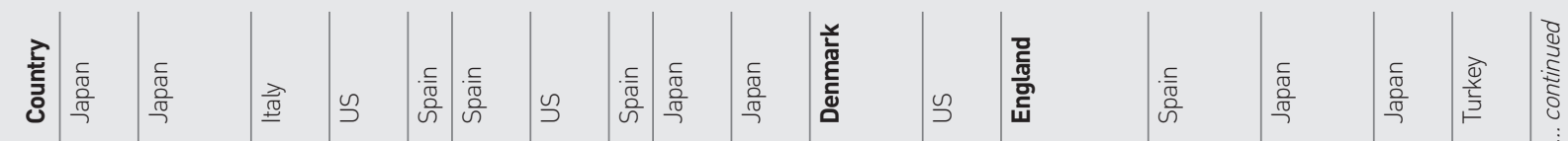

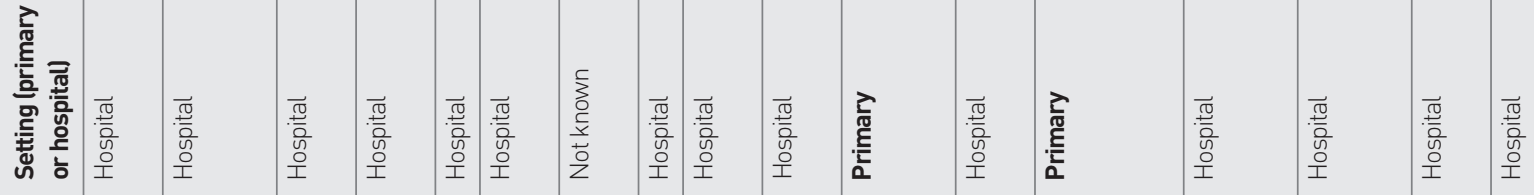

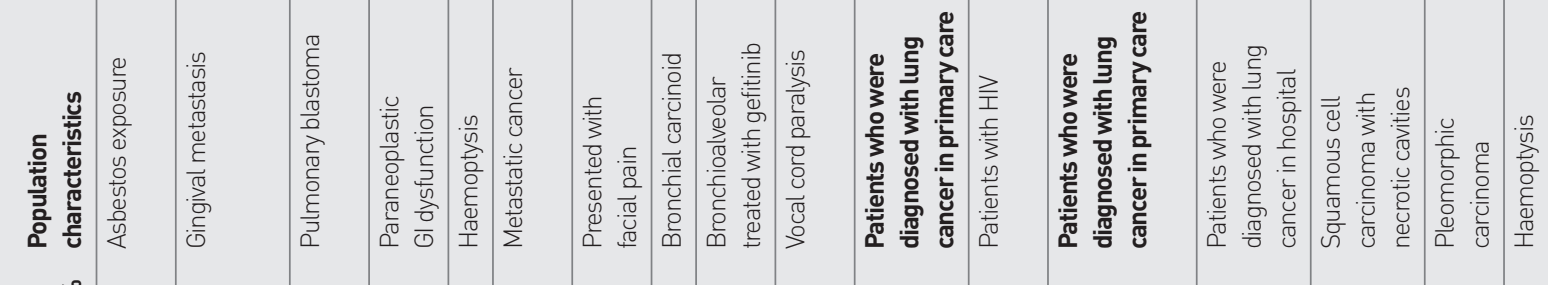

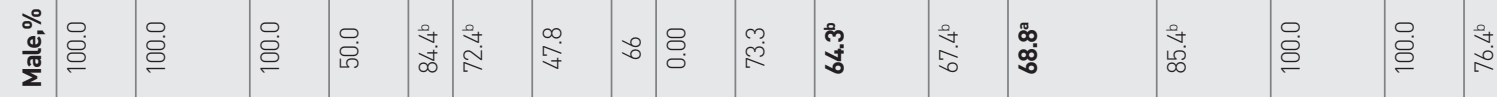

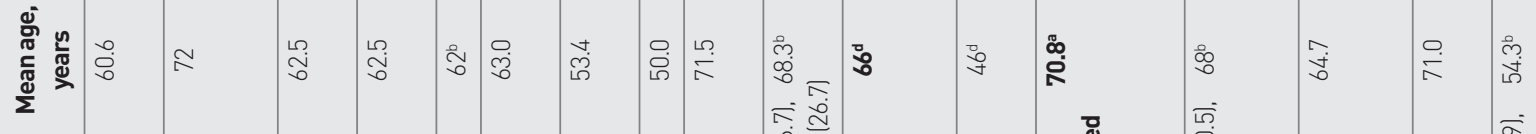
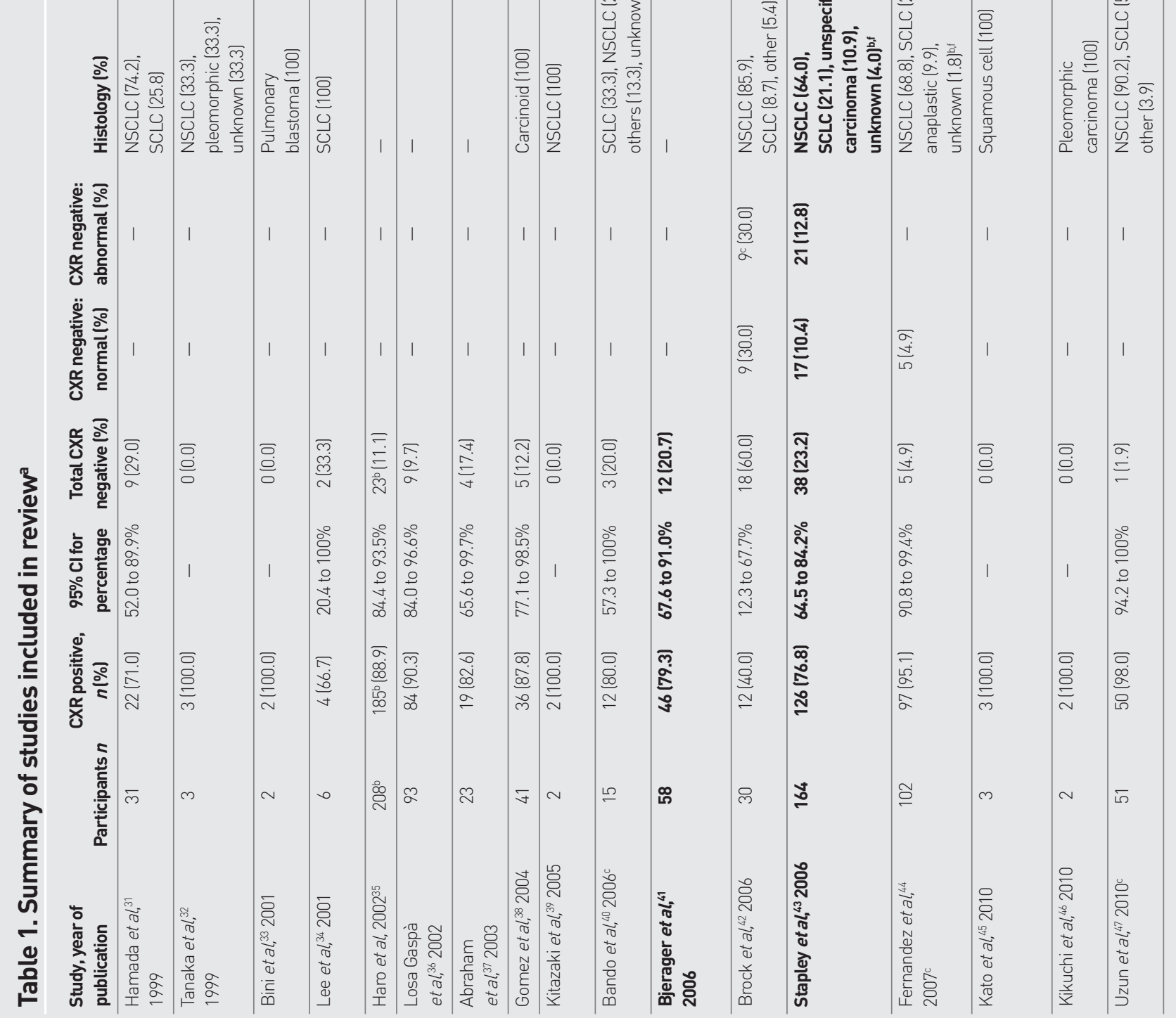


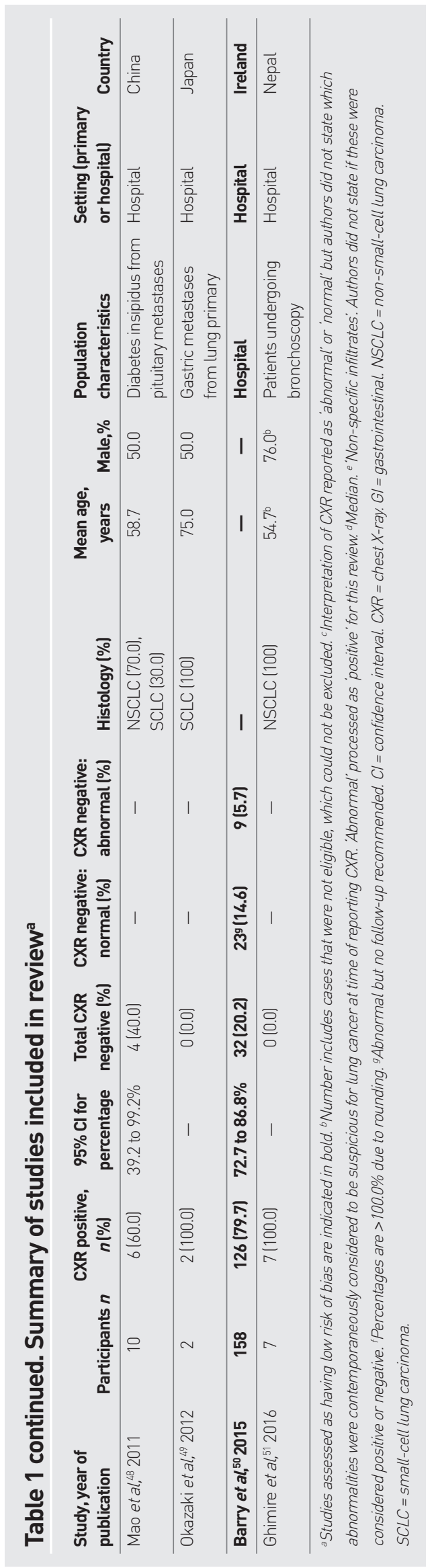

county of Aarhus who had a diagnosis of lung cancer during a 6-month period in $2003 .{ }^{41}$ The purpose of the study was to explore reasons for diagnostic delay in lung cancer. Of 58 patients who had a chest X-ray arranged from general practice, 46 (79.3\%; $95 \% \mathrm{Cl}=67.6$ to 91.0 ) had chest $X$-rays that suggested the possibility of lung cancer, including two cases in which infection was identified with a recommendation for repeat imaging after an appropriate interval. In the remaining $12(20.7 \%)$, chest $X$-rays were reported as raised no suspicion of lung cancer'.

An English retrospective cohort study examined chest $X$-ray results of 164 patients from general practices in a primary care trust diagnosed with lung cancer between January 1998 and September 2002 lpatients aged $\geq 40$ years). ${ }^{43}$ In over three-quarters ( $n=126,76.8 \%$; $95 \% \mathrm{Cl}=64.5$ to $84.2 \%$ ) the chest $X$-ray indicated the possibility of lung cancer, while 38 (23.17\%) patients had a 'negative' chest $X$-ray. Of the 38 'negative' chest $X$-rays, 21 (12.8\%) were categorised as abnormal but not suspicious of malignancy, while 17 (10.4\%) were reported as 'normal'.

A retrospective case note review of all patients diagnosed with lung cancer in a Spanish centre from January 2001 to September 2006 included 102 patients who had a chest X-ray before diagnosis. ${ }^{44} \mathrm{An}$ 'abnormality' was present on 97 (95.1\%) of the patients' chest X-rays; however, this could not be considered synonymous with 'sensitivity' as the authors did not indicate which of the abnormalities were considered to be suspicious for lung cancer when they were reported. The abnormalities were nodules or masses in 53 cases (52.0\%), pleural effusions in $16(15.7 \%)$, an enlarged hilum in 16 (15.7\%), multiple pulmonary metastasis in six (5.9\%), a widened mediastinum in four (3.9\%), and an interstitial infiltration in two (2.0\%).

Finally, a conference abstract reported a retrospective review of chest $X$-ray reports in a secondary care setting in the Republic of Ireland. ${ }^{50}$ The authors identified $126(79.7 \%, 95 \% \mathrm{Cl}=72.7$ to $86.8 \%)$ of 158 patients as likely to have a lung malignancy and/or advised to have repeat imaging. A further 23 (14.6\%) patients had a chest $X$-ray in which the authors refer to lesion not identified' and nine (5.7\%) in which an abnormality was identified but no follow-up recommended.

\section{Quality assessment}

Assessment of quality was undertaken by two of the authors using a modified version of the QUADAS-2 tool, ${ }^{30}$ with 
disagreements between reviewers resolved through discussion. Three studies ${ }^{41,43,50}$ were deemed to have a low risk of bias. A further study was deemed to have a low risk of bias in the selection of patients; 44 however, the reporting of chest X-ray result as normal or abnormal, rather than suspicious or not suspicious for lung cancer, introduced bias that limited applicability for this review. The majority of studies ( $n=17,81.0 \%$ ) were deemed to have a high risk of bias. In particular, these studies included distinct subgroups of the relevant patient population, such as atypical tumour histology, or specific comorbidities and symptom presentations.

\section{DISCUSSION}

\section{Summary}

This systematic review identified three studies that reported sensitivity of chest X-ray and that had a low risk of bias. The sensitivity estimates for these studies were: $79.3 \%(95 \% \mathrm{Cl}=67.6$ to $91.0 \%),{ }^{41}$ $76.8 \%(95 \% \mathrm{Cl}=64.5$ to $84.2 \%),{ }^{43}$ and $79.7 \%$ $(95 \% \mathrm{Cl}=72.7$ to $86.8 \%) .50$

These results suggest that chest $X$-ray fails to identify lung cancer (at least initially) in $>20 \%$ of people who are subsequently diagnosed with lung cancer. All three of these studies were conducted in countries with broadly similar primary care systems (Denmark, England, Republic of Ireland). Two of these studies ${ }^{41,43}$ were derived from primary care settings and, though the remaining study was from a secondary care radiology department, ${ }^{50}$ it is likely that many of the chest $X$-rays performed resulted from primary care referrals.

\section{Strengths and limitations}

This review featured a sensitive and comprehensive search of bibliographic databases and grey literature in order to identify published and unpublished sources. This study is highly relevant both to national cancer policy and everyday clinical practice. With approximately 46700 new diagnoses of lung cancer in the UK per year, ${ }^{2}$ of which approximately $56 \%$ are diagnosed following referral for chest $X$-ray, ${ }^{7}$ these findings suggest that false-negative chest $X$-rays could contribute to a delayed diagnosis for several thousand patients each year.

Diagnostic accuracy was the stated primary outcome of only one study; in most included studies a value of sensitivity was estimated from data reported. These studies were therefore at high risk of bias. Indeed, none conformed to the conventional standards of diagnostic accuracy studies. ${ }^{52}$ While the best available evidence was selected for analysis, many other eligible studies were of poor quality making metaanalysis inappropriate. In order to identify all relevant evidence, the present review included studies from different settings. The different disease prevalence in primary and secondary care is known to impact on test performance, ${ }^{53}$ which could not be accounted for in this review. However, the consistency in the sensitivity estimates from the higher-quality studies is striking. Due to the large number of citations, selection was peer reviewed in only $20 \%$ of cases and data extraction was conducted by one researcher. Notably, 187 citations could not be obtained, reflecting the broad search strategy used and the low threshold used for selection for full-text review. Only about half of those articles ( $n=97,51.2 \%$ ) contained any study data in their abstracts.

\section{Comparison with existing literature}

Several studies have evaluated the performance of chest $X$-ray by re-examining radiographs in the light of a known lung cancer diagnosis. Although such studies were not eligible for this review, that literature provides an important context. Notably, a Dutch retrospective review of radiographs of non-small-cell lung cancer cases ( $n=495)$ reported that $19 \%$ had a nodular lesion that had been 'missed'. ${ }^{54}$

It is possible that lung cancers may not have been present when imaging occurred (interval cancers). A large screening trial concluded that, of those cancers that were not detected on screening chest $\mathrm{X}$-ray but subsequently diagnosed within 1 year, the lung cancer was not visible, even in retrospect, in $65 \%$ of cases. ${ }^{55}$

Separate literature has explored the role of 'observer error' in failing to recognise cancers that were evident in retrospect. Inexperience, poor technique in visual scanning of the image, failures in recognising abnormalities, and of decision making along with lapses of concentration have all been identified as factors contributing to missed lung cancers on chest X-ray. ${ }^{56,57}$

Other studies have considered the characteristics of lesions, which may make them less identifiable. Smaller tumours are identified much less frequently; lesions measuring $<1 \mathrm{~cm}$ in diameter are particularly likely to be missed on chest $\mathrm{X}$-ray compared with other modalities such as CT. ${ }^{54}$

Location is also important, with missed lung cancers frequently located in the upper lobes ${ }^{54,58-61}$ or obscured by overlying anatomy such as ribs, lung vasculature, 


\section{Funding}

Stephen H Bradley and Bethany Shinkins are funded by the multi-institutional CanTest Collaborative, which is funded by Cancer Research UK (reference number: C8640/ A23385). Richard D Neal and William T Hamilton are Associate Directors of the multi-institutional CanTest Collaborative, which is funded by Cancer Research UK (reference number: C8640/A23385).

\section{Ethical approval}

Ethical approval is not required.

\section{Provenance}

Freely submitted; externally peer reviewed.

\section{Competing interests}

Matthew EJ Callister is the chief Investigator for Yorkshire Lung Screening Trial and co-Investigator for Yorkshire Enhanced Stop Smoking Study. Both studies are funded by Yorkshire Cancer Research. The other authors have no competing interests.

\section{Acknowledgements}

The authors are extremely grateful to Monica Koo, Marie Bourne, Nazia Ahmed, Sibel Saya, and Dorota Karasek for their assistance in translation of non-English studies; Judy Wright and Natalie King for their advice regarding the systematic review; and Tracey Farragher for providing additional advice regarding the design of the study. The authors would also like to thank the many authors who kindly provided additional information in order to determine eligibility of their studies for this review.

\section{Discuss this article}

Contribute and read comments about this article: bjgp.org/letters

and the heart. Many missed cancers are located in the hilar regions, where the confluence of complex anatomy makes diagnosis particularly challenging. ${ }^{56}$ The technical quality of the radiograph itself and the positioning of the patient are additional factors that can influence the likelihood of successful detection of lung cancer on chest X-ray. ${ }^{62}$

\section{Implications for research and practice}

Chest X-ray retains a predominant role in UK clinical practice and guidance for the diagnosis of lung cancer. ${ }^{63}$ Most lung cancers are diagnosed following suspicious findings on chest $X$-ray ${ }^{7}$ and increasing the use of chest $X$-ray in primary care has been associated with diagnosis at an earlier stage and reduced mortality. ${ }^{64}$ However, this review suggests that chest $X$-ray may have a false-negative rate of at least $20 \%$. GPs should take limited reassurance from a non-diagnostic chest $X$-ray and consider additional imaging or referral of those at high risk, or re-imaging in the face of continuing symptoms. If chest $\mathrm{X}$-ray were a novel technology, it is debatable whether the available evidence would be deemed sufficient to support its implementation as a diagnostic test for lung cancer. In order to improve the UK's lung cancer outcomes, diagnostic strategies may necessitate widening access to more definitive modalities, such as CT. Although this study has demonstrated a significant false-negative rate for chest X-ray, it is important to recognise that the benefits of increased rates of CT investigation must be balanced against known harms including overdiagnosis and false-positives. ${ }^{65}$ Future work is required to determine which patients can be reasonably followed up by safety netting following an unremarkable chest X-ray and which patients require further investigation. 


\section{REFERENCES}

1. Ferlay J, Soerjomataram I, Dikshit R, et al. Cancer incidence and mortality worldwide: sources, methods and major patterns in GLOBOCAN 2012. Int $J$ Cancer 2015; 136(5): E359-E386.

2. Cancer Research UK. Lung cancer statistics. 2019 https://uww. cancerresearchuk.org/health-professional/cancer-statistics/statistics-bycancer-type/lung-cancer laccessed 19 Sep 2019).

3. Cancer Research UK. Breast cancer survival statistics. 2014. https://www cancerresearchuk.org/health-professional/cancer-statistics/statistics-bycancer-type/breast-cancer/survival\#heading-Two laccessed 19 Sep 2019).

4. Rubin $\mathrm{G}$, Berendsen $\mathrm{A}$, Crawford $\mathrm{SM}$, et al. The expanding role of primary care in cancer control. Lancet Oncol 2015; 16(12): 1231-1272.

5. Hamilton W. Cancer diagnosis in primary care. Br J Gen Pract 2010; DOI: https://doi.org/10.3399/bjgp10X483175.

6. Public Health England. Patient dose information: guidance; X-ray examinations. 2008. https://www.gov.uk/government/publications/medical-radiation-patientdoses/patient-dose-information-guidance laccessed 19 Sep 2019).

7. Aslam R, Kennedy MP, Bhartia B, et al. The radiological route to diagnosis of lung cancer patients. Thorax 2018; 73(Suppl 4): A70-A71.

8. National Institute for Health and Care Excellence. Lung cancer: diagnosis and management. CG121. London: NICE, 2011. https://www.nice.org.uk/guidance/ cg121/chapter/1-Guidance laccessed 19 Sep 2019).

9. Arnold M, Rutherford MJ, Bardot A, et al. Progress in cancer survival, mortality, and incidence in seven high-income countries 1995-2014 (ICBP SURVMARK-2): a population-based study. Lancet Oncol 2019; https://doi.org/10.1016/S14702045(19)30456-5.

10. Eurostat, Statistics Explained. Healthcare resource statistics-technical resources and medical technology. 2019; https://ec.europa.eu/eurostat/ statistics-explained/index.php/Healthcare_resource_statistics_-_technical_ resources_and_medical_technology\#Availability_of_technical_resources_in_ hospitals. (accessed Oct 2019).

11. Bradley S, Grice A, Lopez RR, et al. Diagnostic accuracy of low dose CT versus chest $x$-ray and false negative rates for chest $x$-ray in lung cancer. 2019. https:// unw.crd.york.ac.uk/prospero/display_record.php?RecordID=69629 laccessed 19 Sep 2019).

12. Royal College of Radiologists. https://www.rcr.ac.uk laccessed 19 Sep 2019).

13. American College of Radiology. https://www.acr.org/ (accessed 19 Sep 2019).

14. American Society of Clinical Oncology. https://www.asco.org/ laccessed 19 Sep 2019).

15. ASTRO: American Society of Radiation Oncology. https://www.astro.org laccessed 19 Sep 2019].

16. British Institute of Radiology. https://bir.org.uk laccessed 19 Sep 2019).

17. European Society for Radiotherapy Oncology. https://www.estro.org laccessed 19 Sep 2019).

18. European Society for Medical Oncology. https://www.esmo.org laccessed 19 Sep 2019).

19. International Society of Radiology. http://isradiology.org/2017/isr/index.php (accessed 19 Sep 2019)

20. International Association for the Study of Lung Cancer. https://mww.iaslc.org (accessed 19 Sep 2019).

21. British Thoracic Society. https://www.brit-thoracic.org.uk laccessed 19 Sep 2019).

22. British Thoracic Oncology Group. https://www.btog.org laccessed 19 Sep 2019)

23. Public Health England. National Cancer Registration Analysis Service. 2016. https://uww.gov.uk/guidance/national-cancer-registration-and-analysisservice-ncras (accessed 19 Sep 2019).

24. European Respiratory Society. https://www.ersnet.org (accessed 19 Sep 2019).

25. American Thoracic Society. http://www.thoracic.org laccessed 19 Sep 2019).

26. Cancer and Primary Care Research International Network. http://www.ca-pri. org laccessed 19 Sep 2019).

27. Detterbeck FC, Gibson CJ. Turning gray: the natural history of lung cancer over time. J Thorac Oncol 2008; 3(7): 781-792.

28. Chien C-R, Lai M-S, Chen TH-H. Estimation of mean sojourn time for lung cancer by chest $\mathrm{X}$-ray screening with a Bayesian approach. Lung Cancer 2008; 62(2): $215-220$.
29. Wu D, Erwin D, Rosner GL. Sojurn time and lead time projection in lung cancer screening. Lung Cancer 2011; 72(3): 322-326.

30. Whiting PF, Rutjes AWS, Westwood ME, et al. QUADAS-2: a revised tool for the quality assessment of diagnostic accuracy studies. Ann Intern Med 2011; 155(8): 529-536

31. Hamada K, Tokuyama T, Okamoto Y, et al. A clinicopathological study of lung cancer patients with occupational exposure to chrysotile asbestos fibers. Intern Med 1999; 38(10): 780-784.

32. Tanaka M, Sawada M, Inase N, et al. Cases of gingival metastasis from lung cancer and a review of the literature. (In Japanese). Japanese Journal of Lung Cancer 1999; 39(3): 323-329.

33. Bini A, Ansaloni L, Grani G, et al. Pulmonary blastoma: report of two cases. Sur Today 2001; 31(5): 438-442.

34. Lee HR, Lennon VA, Camilleri M, Prather CM. Paraneoplastic gastrointestinal motor dysfunction: clinical and laboratory characteristics. Am J Gastroenterol 2001; 96(2): 373-379

35. Haro M, Jimenez J, Tornero A, et al. Usefulness of computerized tomography and bronchoscopy in patients with hemoptysis. Analysis of 482 cases. (In Spanish). An Med Interna 2002; 19(2): 59-65.

36. Losa Gaspà F, Germá JR, Albareda JM, et al. Metastatic cancer presentation. Validation of a diagnostic algorithm with 221 consecutive patients. (In Spanish). Rev Clin Esp 2002; 202(6): 313-319.

37. Abraham PJ, Capobianco DJ, Cheshire WP. Facial pain as the presenting symptom of lung carcinoma with normal chest radiograph. Headache 2003 43(5): 499-504.

38. Gomez A, Zalacain R, Cabriada V, et al. Bronchial carcinoid tumors. Analysis of 41 cases. (In Spanish). Rev Clin Esp 2004; 204(4): 202-205.

39. Kitazaki T, Fukuda M, Soda H, Kohno S. Novel effects of gefitinib on mucin production in bronchioloalveolar carcinoma; two case reports. Lung Cancer 2005; 49(1): 125-128

40. Bando H, Nishio T, Bamba H, et al. Vocal fold paralysis as a sign of chest diseases: a 15-year retrospective study. World J Surgery 2006; 30(3): 293-298.

41. Bjerager $M$, Palshof $T$, Dahl $R$, et al. Delay in diagnosis of lung cancer in general practice. Br J Gen Pract 2006; 56(532): 863-868.

42. Brock MV, Hooker CM, Engels EA, et al. Delayed diagnosis and elevated mortality in an urban population with HIV and lung cancer: implications for patient care. J Acquir Immume Defic Syndr 2006; 43(1): 47-55.

43. Stapley S, Sharp D, Hamilton W. Negative chest X-rays in primary care patients with lung cancer. Br J Gen Pract 2006; 56(529): 570-573.

44. Fernandez V, Alonso JL, Munuera L, et al. Analysis of lung cancer cases diagnosed in an internal medicine department: from January 2001 to September 2006. (In Spanish). An Sist Sanit Navar 2007; 30(3): 353-362.

45. Kato T, Narita K, Ohara K. Three cases of squamous cell carcinomas which enlarged rapidly with necrotic cavities after bronchoscopy. (In Japanese). Japanese Journal of Lung Cancer 2010; 50(6): 822-827.

46. Kikuchi R, Isowa N, Tokuyasu H, et al. Three cases of resected pleomorphic carcinoma. Ann Thorac Cardiovasc Surg 2010; 16(4): 264-269.

47. Uzun O, Atasoy Y, Findik S, et al. A prospective evaluation of hemoptysis cases in a tertiary referral hospital. Clin Resp J 2010; 4(3): 131-138.

48. Mao JF, Zhang JL, Nie M, et al. Diabetes insipidus as the first symptom caused by lung cancer metastasis to the pituitary glands: clinical presentations, diagnosis, and management. J Postgrad Med 2011; 57(4): 302-306.

49. Okazaki A, Araya T, Sakai A, et al. Two cases of small cell lung cancer with metastasis to the stomach at initial diagnosis. (In Japanese). Japanese Journal of Lung Cancer 2012; 52(2): 220-225.

50. Barry C, Bergin D. Non-detected primary lung cancers on chest $x$-ray: 3 year retrospective review in university hospital. Ir J Med Sci2015; 1: S262.

51. Ghimire RH, Bhatta N, Koirala P, et al. Outcomes bronchoscopic evaluation in a university hospital. JNMA J Nepal Med Assoc 2016; 55(204): 51-54.

52. Bossuyt PM, Reitsma JB, Bruns DE, et al. STARD 2015: an updated list of essential items for reporting diagnostic accuracy studies. BMJ 2015; 351: h5527.

53. Bentley TG, Catanzaro A, Ganiats TG. Implications of the impact of prevalence on test thresholds and outcomes: lessons from tuberculosis. BMC Res Notes 2012; 5(1): 563 .

54. Quekel LGBA, Kessels AGH, Goei R, van Engelshoven JMA. Miss rate of lung cancer on the chest radiograph in clinical practice. Chest 1999; 115(3): 720724 
55. Kvale PA, Johnson CC, Tammemägi M, et al. Interval lung cancers not detected on screening chest X-rays: how are they different? Lung Cancer 2014; 86(1): 41-46.

56. Del Ciello A, Franchi P, Contegiacomo A, et al. Missed lung cancer: when, where, and why? Diag Interv Radiol 2017; 23(2): 118-126.

57. Kundel HL, La Follette PS Jr. Visual search patterns and experience with radiological images. Radiology 1972; 103(3): 523-528.

58. Austin JH, Romney BM, Goldsmith LS. Missed bronchogenic carcinoma: radiographic findings in 27 patients with a potentially resectable lesion evident in retrospect. Radiology 1992; 182(1): 115-122.

59. Shah PK, Austin JHM, White CS, et al. Missed non-small cell lung cancer: radiographic findings of potentially resectable lesions evident only in retrospect. Radiology 2003; 226(1): 235-241.

60. Wu MH, Gotway MB, Lee TJ, et al. Features of non-small cell lung carcinomas overlooked at digital chest radiography. Clin Radiology 2008; 63(5): 518-528.
61. Theros EG. 1976 Caldwell Lecture: varying manifestation of peripheral pulmonary neoplasms: a radiologic-pathologic correlative study. AJR Am J Roentgen 1977; 128(6): 893-914.

62. Brogdon B, Kelsey C, Moseley RD Jr. Factors affecting perception of pulmonary lesions. Radiol Clin North Am 1983; 21(4): 633-654.

63. National Institute for Health and Care Excellence. Suspected cancer: recognition and referral. NG12. London: NICE, 2015. https://uww.nice.org.uk/guidance/ng12 (accessed 19 Sep 2019).

64. Kennedy MPT, Cheyne L, Darby M, et al. Lung cancer stage-shift following a symptom awareness campaign. Thorax 2018; 73(12): 1128-1136.

65. Heleno B, Siersma V, Brodersen J. Estimation of overdiagnosis of lung cancer in low-dose computed tomography screening: a secondary analysis of the Danish lung cancer screening trial. JAMA Intern Med 2018; 178(10): 1420-1422. 